\title{
PENGARUH DEPRESI POST PARTUM DAN MOBILISASI DINI TERHADAP INVOLUSI UTERI PADA POST SECTIO CAESAREA
}

\author{
Effect Of Post Partum Depression And Early Mobilization On Uterial Involution In Post \\ Sectio Cesarea
}

\author{
Yuni Khoirul Waroh ${ }^{1}$ \\ 1. Universitas PGRI Adi Buana Surabaya
}

\section{Riwayat artikel}

Diajukan: September 2020

Diterima: Maret 2021.

\section{PenulisKorespondensi: \\ - Yuni Khoirul Waroh \\ - Universitas PGRI Adi Buana Surabaya \\ - yunikhoirulwaroh@un ipasby.ac.id}

\begin{tabular}{llr}
\multicolumn{2}{l}{ Kata Kunci: } & \\
Depresi & Post & Partum, \\
Mobilisasi & Dini, & Involusi \\
Uteri, & Post & Sectio \\
Caesaraea & &
\end{tabular}

\begin{abstract}
Abstrak
Persalinan operatif pada saat ini dianggap sebagai alternatif paling utama untuk menekan angka kesakitan akibat persalinan fisiologis, sehingga keadaan ini meningkatkan angka kejadian persalinan operatif tanpa indikasi medis. Asuhan pasca persalinan operatif sangat banyak, sinhingga dibutuhkan tekat dari ibu pasca salin dengan tindakan operatif untuk mampu mengatasi berbagai masalah yang ditimbulkan akobatnya. Salah satu masalah yang diakibatkan adalah rasa nyeri yang ini bisa berimbas pada emosi pasien dan juga mobilisasi dini yang kesemuanya mempengaruhi involusi uteri. Tujuan penelitian ini untuk mengetahui pengaruh depresi post partum dan mobilisasi dini terhadap involusi uteri pada ibu post sectio cesarea di Rumah Sakit Ibu dan Anak Cempaka Putih Surabaya. Penelitian ini merupakan penelitian analitik dengan metide observasional, yang dimana instrument yang digunakan adalah Edinburgh Postpartum Depresion Syndrome (EPDS), Kuesioner mobilisasi dini dan pemeriksaan Tinggi Fundus Uteri. Uji statistik yang digunakan Regresi Linier Berganda. Hasil penelitian menunjukkan nilai sig $=0,029<0.05$, yang artinya terdapat pengaruh antara depresi post partum, mobilisasi dini terhadap involusi uteri pada ibu Post SC di RSIA Cempaka Putih.Kesimpulannya asuhan kebidanan yang harus diberikan pada ibu post sectio Caesarea bukan hanya pada saat tindakan operatif selesai, melainkan harus dimulai dengan membrikan informasi yang akurat menyangkut hal-hal yang harus dipersiapkan pada saat pre operasi dan pasca operasi , sehingga dapat mensuport masa pemulihan .
\end{abstract}

\section{Abstract}

Operative delivery is currently considered as the main alternative to reduce morbidity due to physiological labor, so that this situation increases the incidence of operative delivery without medical indication. Post-operative care is very much, so it requires determination from postpartum mothers with operative measures to be able to overcome the various problems caused by treatment. One of the resulting problems is pain, which can affect the patient's emotions and also early mobilization, all of which affect the involution of the uterus. The purpose of this study was to determine the effect of post partum depression and early mobilization on uterine involution in post-sectio cesarean mothers at the Cempaka Putih Mother and Child Hospital Surabaya. This study is an analytical study with an observational method, in which the instruments used are the Edinburgh Postpartum Depression Syndrome (EPDS), early mobilization questionnaire and examination of the uterine fundus height. The statistical test used is Multiple Linear Regression. The results showed the value of sig $=0.029<0.05$, which means that there is an influence between post partum depression, early mobilization of uterine involution in Post SC mothers at RSIA Cempaka Putih. finished, but must be started by providing accurate information regarding things that must be prepared during preoperative and postoperative time, so that it can support the recovery period. 


\section{Pendahuluan}

Operasi caesar adalah prosedur bedah yang dilakukan secara efektif sebagai upaya untuk menurunkan angka kematian ibu dan bayi baru lahir dengan indikasi medis.

Pada saat ini terjadi peningkatan jumlah persalinan dengan menggunakan metode operatif. Faktor-faktor yang mempengaruhi terjadinya peningkatan operasi caesar sangat komplek. Faktor yang berkaitan dengan klinis antara lain: obesitas, kehamilan ganda, peningkatan nulipara atau wanita yang lebih tua untuk melahirkan. Adapun faktor non klinis antara lain: wanita yang ingin menentukan bagaimana ketika anak mereka lahir, faktor dokter, meningkatnya rasa takut intervensi medis, pekerjaan, ekonomi serta faktor sosial yang lain.

Menurut data Profil Kesehatan Indonesia tahun 2019 target Angka Kematian Ibu tahun 2024 adalah 183/100.000 kelahiran hidup dan tahun 2030 diharapkan menjadi 131 per 100.000 kelahiran hidup.sedangkan penyebab kematian ibu terbanyak adalah perdarahan 91.280 kasus), hipertensi dalam kehamilan (1.066 kasus) dan infeksi (207 kasus)

Berdasarkan hasi Riset kesehatan dasar tahun 2018 , proporsi metode persainan dengan operasi pada erempuan usia 10-54 tahun sebesar $22,36 \%$, dan 25,71 $\%$ didapatkan di perkotaan.

Salah satu efek dari tindakan persalinan operatif adalah bisa menimbulkan infeksi,apabila tidak diberikan asuhan yang optimal pada masa pemulihan.

Depresi post partum merupakan episode pertama dari depresi atau bisa didahului oleh gejala depresi pada kehamilan sekarang, kehamilan sebelumnya, atau pada periode postpartum sebelumnya, dan bisa juga terjadi dalam konteks seumur hidup.

Dari uraian di atas dapat diambil kesimpulan masih banyak pekerjaan rumah yang harus diselesaikan oleh petugas kesehatan khususnya bidan dan juga mengeliminasi persalinan operatif tanpa indikasi medis, inilah yang menjadi landasan penelitian.

\section{Metodologi}

Jenis penelitian ini adalah observasi analitik dengan menggunakan desain "cross sectional". Data didapatkan melalui wawancara kepada responden melalui angket dan pemeriksaan fisik.

Penelitian dilaksanakan di Rumah Sakir Ibu dan Anak Cempaka Putih Surabaya pada bulan Januari 2020- Desember 2021.

Pengambilan sampel pada penelitian ini menggunakan probability sampling. Besar smpel pada penelitian ini sebanyak 16 ibu post Sectio Caesarea

Uji statistik pada analisi multivariat menggunakan Regresi Linier Berganda .

\section{Hasil dan Pembahasan}

\section{Data Umum}

a. Umur Ibu

Tabel 1 Distribusi Frekuensi Umur Ibu Post SC di RSIA Cempaka Putih

\begin{tabular}{ccc}
\hline Umur Ibu & Frekuensi & Presentase (\%) \\
\hline 15-20 tahun & 0 & $0,0 \%$ \\
$21-35$ tahun & 13 & $81,3 \%$ \\
$36-45$ tahun & 3 & $18,7 \%$ \\
\hline Jumlah & $\mathbf{1 6}$ & $\mathbf{1 0 0}$ \\
\hline
\end{tabular}

Sumber : Data Primer 2020

Dari tabel menunjukkan bahwa sebagian besar umur ibu Post SC di RSIA Cempaka Putih berumur 21-35 tahun sebanyak $13 \mathrm{ibu}$ $(81,3 \%)$.

\section{b. Pendidikan}

Tabel 2 Distribusi Frekuensi Pendidikan Ibu Post SC di RSIA Cempaka Putih

\begin{tabular}{ccc}
\hline $\begin{array}{c}\text { Pendidikan } \\
\text { Ibu }\end{array}$ & Frekuensi & Presentase (\%) \\
\hline Dasar & 0 & $0,0 \%$ \\
Menengah & 6 & $37,5 \%$ \\
Perguruan & 10 & $62,5 \%$ \\
Tinggi & & \\
\hline Jumlah & $\mathbf{1 6}$ & $\mathbf{1 0 0}$ \\
\hline
\end{tabular}

Sumber : Data Primer 2020

Dari tabel menunjukkan bahwa sebagian besar pendidikan ibu Post SC di RSIA Cempaka Putih adalah pendidikan tinggi sebanyak $10 \mathrm{ibu}(62,5 \%)$. 


\section{c. Paritas}

Tabel 3 Distribusi Frekuensi Paritas Ibu Post SC di RSIA Cempaka Putih

\begin{tabular}{ccc}
\hline Paritas Ibu & Frekuensi & $\begin{array}{c}\text { Presentase } \\
(\boldsymbol{\%})\end{array}$ \\
\hline Primipara & 6 & $37,5 \%$ \\
Multipara & 9 & $56,3 \%$ \\
Grandemultipara & 1 & $6,2 \%$ \\
\hline Jumlah & $\mathbf{1 6}$ & $\mathbf{1 0 0}$ \\
\hline
\end{tabular}

Sumber : Data Primer 2020

Dari tabel menunjukkan bahwa sebagian besar paritas ibu Post SC di RSIA Cempaka Putih adalah multipara sebanyak 9 ibu $(56,3 \%)$.

\section{Data Khusus}

a. Depresi Post Partum

Tabel 4 Distribusi Frekuensi Depresi Post Partum Ibu Post SC di RSIA Cempaka Putih

\begin{tabular}{ccc}
\hline $\begin{array}{c}\text { Depresi Post } \\
\text { Partum }\end{array}$ & Frekuensi & Presentase (\%) \\
\hline $\begin{array}{c}\text { Tidak } \\
\text { beresiko }\end{array}$ & 10 & $62,5 \%$ \\
$\begin{array}{c}\text { Depresi } \\
\text { sedang }\end{array}$ & 4 & $25,0 \%$ \\
Depresi berat & 2 & $12,5 \%$ \\
\hline Jumlah & $\mathbf{1 6}$ & $\mathbf{1 0 0}$ \\
\hline
\end{tabular}

Sumber : Data Primer 2020

Dari tabel menunjukkan bahwa sebagian kecil ibu Post SC di RSIA Cempaka Putih mengalami depresi berat sebanyak 2 ibu (12,5\%).

\section{b. Mobilisasi Dini}

Tabel 5 Distribusi Frekuensi Mobilisasi Dini Ibu Post SC di RSIA Cempaka Putih

\begin{tabular}{ccc}
\hline $\begin{array}{c}\text { Mobilisasi } \\
\text { Dini }\end{array}$ & Frekuensi & Presentase (\%) \\
\hline Baik & 8 & $50,0 \%$ \\
Tidak Baik & 8 & $50,0 \%$ \\
\hline Jumlah & $\mathbf{1 6}$ & $\mathbf{1 0 0}$ \\
\hline
\end{tabular}

Sumber : Data Primer 2020

Dari tabel menunjukkan bahwa hasilnya berimbang antara yang melakukan mobilisasi dini dengan baik dan tidak baik pada ibu Post SC di RSIA Cempaka Putih sebanyak 8 ibu $(50,0 \%)$.

\section{c. Tinggi Fundus Uteri}

Tabel 6 Distribusi Frekuensi Tinggi Fundus Uteri Ibu Post SC di RSIA Cempaka Putih

\begin{tabular}{ccc}
\hline $\begin{array}{c}\text { Tinggi } \\
\text { Fundus Uteri }\end{array}$ & Frekuensi & Presentase (\%) \\
\hline Sesuai & 6 & $37,5 \%$ \\
Tidak sesuai & 10 & $62,5 \%$ \\
\hline Jumlah & $\mathbf{1 6}$ & $\mathbf{1 0 0}$ \\
\hline
\end{tabular}

Sumber : Data Primer 2020

Dari tabel menunjukkan bahwa sebagian besar Tinggi Fundus Uteri ibu Post SC di RSIA Cempaka Putih tidak sesuai sebanyak $10 \mathrm{ibu}(62,5 \%)$.

\section{d. Pengaruh Depresi Post Partum terhadap Involusi Uteri}

Tabel 7 Pengaruh Depresi Post Partum terhadap Involusi Uteri

\begin{tabular}{llr|r} 
& & DPP & \multicolumn{1}{r}{ Involusi Uteri } \\
\hline DPP & $\begin{array}{l}\text { Pearson } \\
\text { Correlation }\end{array}$ & 1 & .365 \\
\cline { 2 - 4 } & Sig. (2-tailed) & & .164 \\
\cline { 2 - 4 } & $\mathrm{N}$ & 16 & 16 \\
\hline $\begin{array}{l}\text { Involusi } \\
\text { Uteri }\end{array}$ & $\begin{array}{l}\text { Pearson } \\
\text { Correlation }\end{array}$ & .365 & 1 \\
\cline { 2 - 4 } & Sig. (2-tailed) & .164 & 16 \\
\cline { 2 - 4 } & $\mathrm{N}$ & 16 & \\
\hline
\end{tabular}

Sumber : Data Primer 2020

Dari tabel menunjukkan bahwa dari uji statistik Pearson menunjukkan bahwa nilai sig $=0,164$ $>0.05$ yang artinya tidak terdapat pengaruh antara depresi post partum dengan involusi uteri pada ibu Post SC di RSIA Cempaka Putih.

\section{e. Pengaruh Mobilisasi Dini terhadap Involusi Uteri}

Tabel 8 Pengaruh Mobilisasi Dini dengan Involusi Uteri

\begin{tabular}{|c|c|c|c|}
\hline & & Mobilisasi & $\begin{array}{l}\text { Involusi } \\
\text { Uteri }\end{array}$ \\
\hline \multirow[t]{3}{*}{$\begin{array}{l}\text { Mobilis } \\
\text { asi }\end{array}$} & $\begin{array}{l}\text { Pearson } \\
\text { Correlation }\end{array}$ & 1 & $.516^{*}$ \\
\hline & Sig. (2-tailed) & & .041 \\
\hline & $\mathrm{N}$ & 16 & 16 \\
\hline \multirow[t]{3}{*}{$\begin{array}{l}\text { Involusi } \\
\text { Uteri }\end{array}$} & $\begin{array}{l}\text { Pearson } \\
\text { Correlation }\end{array}$ & $.516^{*}$ & 1 \\
\hline & Sig. (2-tailed) & .041 & \\
\hline & $\mathrm{N}$ & 16 & 16 \\
\hline
\end{tabular}


Dari tabel menunjukkan bahwa dari uji statistik Pearson menunjukkan bahwa nilai sig $=0,041<0.05$, yang artinya terdapat pengaruh , dengan tingkat korelasi sedang antara mobilisasi dini dengan involusi uteri pada ibu Post SC di RSIA Cempaka Putih.

\section{f.Pengaruh Deresi Post Partum, Mobilisasi Dini terhadap Involusi Uteri \\ Tabel 9 Uji Linier Berganda}

\begin{tabular}{|c|c|c|c|c|c|}
\hline \multicolumn{6}{|c|}{ ANOVA $^{a}$} \\
\hline Model & $\begin{array}{c}\text { Sum } \\
\text { of } \\
\text { Squar } \\
\text { es }\end{array}$ & $\mathrm{df}$ & $\begin{array}{l}\text { Mean } \\
\text { Square }\end{array}$ & $\mathrm{F}$ & Sig. \\
\hline $\begin{array}{l}1 \text { Regressio } \\
\mathrm{n}\end{array}$ & 1.683 & 2 & .841 & 4.720 & $.029^{\mathrm{b}}$ \\
\hline Residual & 2.317 & 13 & .178 & & \\
\hline Total & 4.000 & 15 & & & \\
\hline
\end{tabular}

Sumber : Data Primer 2020

Dari tabel 9 dari uji statistik Regresi linier berganda menunjukkan nilai sig $=0,029<$ 0.05 , yang artinya terdapat pengaruh antara depresi post partum, mobilisasi dini terhadap involusi uteri pada ibu Post SC di RSIA Cempaka Putih.

\section{Depresi Post Partum}

Pada tabel 4 menunjukkan bahwa sebagian kecil ibu Post SC di RSIA Cempaka Putih mengalami depresi berat sebanyak $2 \mathrm{ibu}(12,5 \%)$.

Hasil penelitian Wahyuntari, Evi, et al. (2019) menyimpulkan bahwa tidak ada korelasi jenis persalinan dengan kejadian depresi post partum.

Menurut T. W. Farida Mari'pi (2020) menyatakan jenis persalinan berkorelasi dengan kejadian postpartum blues pada ibu nifas di Rumah Sakit Daerah Balung Kabupaten Jember. Jenis persalinan dapat mempengaruhi kejadian postpartum blues karena seseorang memiliki pengalaman yang buruk sehingga menyebabkan trauma psikis yang dapat menimbulkan kemampuan ibu dalam merawat diri dan bayi akan berkurang.

Dalam penelitian ini terdeskripsi bahwa sebagian kecil ibu yang mengalami depresi berat.Pada saat ini metode persalinan sectio secarean tidak lagi dianggap sebagai suatu hal yang menunjukkan keadaan patologis yang bisa mengancam nyawa pasien, justru persalinan sectio secarean sekarang menjadi trend di kalangan masyarakat terutama pada ekonomi menengah ke atas sebagai alternatif utama untuk proses kelahiran dalam rangka mengurangi trauma psikologis dan juga biologis pada persalinan normal, akhirnya tidak menimbulkan efek psikologis yang cukup besar pada kesembuhan ibu setelah operasi.

\section{Mobilisasi Dini}

Pada tabel 5 menunjukkan bahwa hasilnya berimbang antara yang melakukan mobilisasi dini dengan baik dan tidak baik pada ibu Post SC di RSIA Cempaka Putih sebanyak 8 ibu (50,0\%).

Hasil penelitian Rottie , dkk (2019) menunjukkan bahwa mobillisasi dini mempengaruhi penyembuhan luka post sectio caesarea..

Menurut Saleh, dkk (2020) terdapat hubungan yang signifikan antara mobilisasi dini dengan proses penyembuhan pada ibu pasca operasi Sectio Caesarea, faktor-faktor yang perlu diperhatikan dalam pemulihan keadaan luka pasca operasi yaitu waktu, gerakan fisik, peninjauan luka, dan gejala klinis infeksi pada luka untuk meningkatkan efektifitas dan efisiensi penyembuhan luka pasca operasi Sectio Caesarea.

Menurut Rahayu ,et al (2019) terdapat hubungan antara pengetahuan dan perilaku ibu post sectio caesarea dalam melakukan mobilisasi dini[9]

Dalam penelitian ini didapatkan hasil berimbang antara yang melakukan mobilisasi dini dengan baik dengan yang tidak baik. Dari pengamatan peneliti salah satu faktor yang memegang peranan penting untuk 
menginformasikan sekaligus membimbing langlah-langkah dalam mobilisasi dini pada pasien post sectio secarean adalah tenaga kesehatan dalam hal ini bidan,perawat, dokter kandungan, dan dokter anestesi, sehingga pasien bisa melewati masa penyembuhan luka operasi dengan baik, tanpa berefek pada aktivitas mobilisasi organ-organ yang lain.

\section{Involusi Uteri}

Pada tabel 6 menunjukkan bahwa sebagian besar involusi uteri ibu Post SC di RSIA Cempaka Putih yang tidak sesuai sebanyak $10 \mathrm{ibu}(62,5 \%)$.

Menurut Lisnawaty, L, dkk (2015) terdapat pengaruh antara mobilisasi dini, inisiasi menyusui dini, dan paritas terhadap involusi uterus di RSKD Ibu dan Anak Pertiwi Makassar.

Menurut Rohmawati, I, dkk (2019) ada pengaruh antara senam nifas dan involusi uteri pada ibu primipara post SC yang berusia 20-35 tahun. Untuk tercapainya upaya pemulihan dibutuhkan penyuluhan dan skrinning tinggi dalam persalinan dan nifas guna mengurangi resiko komplikasi.

Dalam penelitian ini didapatkan sebagian besar involusi uteri tidak sesuai , yang dimana hal ini bisa dipengaruhi kurangnya pengetahuan pasien tentang hal-hal yang harus dilakukan pada saat post operasi hari pertama, yang dimana aktivitas ini diperlukan untuk kembalinya oragan reproduksi ke posisi semula, mencegah terjadinya komplikasi

\section{Pengaruh Depresi Post Partum terhadap Involusi Uteri}

Pada tabel 7 menunjukkan bahwa dari uji statistik Pearson menunjukkan bahwa nilai sig $=0,164$ $>0.05$, yang artinya tidak terdapat pengaruh antara depresi post partum dengan involusi uteri pada ibu Post SC di RSIA Cempaka Putih.

Menurut (Yim et al., 2015)menyimpulkan bahwa ada terdapat hubungan antara oksitosin perinatal yang rendah dengan gejala depresi post partum, sedangkan untuk prolaktin disimpulkan terdapat hubungan terbalik yang signifikan yang apabila dilakukan penilaian pada kurun waktu 4 sampai 6 minggu pasca persalinan.

Menurut Silalaen, S., \& Nurchayati, S. (2014) bahwa mekanisme koping yang digunakan ibu yang mengalami depresi post partum ada 2, yaitu dengan koping adaptif dan koping maladaptif.

Hal ini berbeda dengan yang ditemukan di lahan penelitian , dimana ditemukan tidak ada pengaruh antara depresi post partum dengan involusi uteri. Kondisi ini bisa dipengaruhi karena yang menjadi responden pada penelitian ini adalah ibu post sectio secarean yang baru menginjak hari pertama,dan juga karakteristik wanita di Indonesia yang mempunyai mekanisme koping yang baik dalam mengurangi tekanan psikologisnya.

5. Pengaruh Mobilisasi Dini terhadap Involusi Uteri

Pada tabel 8 menunjukkan bahwa dari uji statistik Pearson menunjukkan bahwa nilai sig $=0,041<$ 0.05 , yang artinya terdapat hubungan , dengan tingkat korelasi sedang antara mobilisasi dini dengan involusi uteri pada ibu Post SC di RSIA Cempaka Putih.

Menurut Habib and Ituk,(2018) menyatakan bahwa direkomendasikan pelepasan kateter urin dan mobilisasi dini dalam 24 jam awal pasca operasi guna pengembalian organ reproduksi ke posisi awal.

Menurut Delvira, W., \& AGUS, F. (2015) menyimpulkan Terdapat hubunganyang signifikan antara mobilisasi dini terhadap penyembuhan luka post section caesarea di RS Syafira Pekanbaru.

Dalam penelitian ini didapatkan ada pengaruh antara mobilisasi dini dengan involusi uteri, meskipun pada kenyataannya peneliti menemukan 
bahwa pasien post sectio secarean belum melakukan mobilisasi dini pada saat 24 jam post partum secara sistematis.

6. Pengaruh Depresi Post Partum dan Mobilisasi Dini terhadap Involusi Uteri

Pada tabel 9 menunjukkan bahwa dari uji statistik Regresi linier berganda menunjukkan nilai sig $=0,029$ $<0.05$, yang artinya terdapat pengaruh antara depresi post partum, mobilisasi dini terhadap involusi uteri pada ibu Post SC di RSIA Cempaka Putih.

Menurut (Kustini, 2018) menunjukkan bahwa ada perbedaan involusi uteri pada ibu nifas fisiologis dan ibu nifas post SC, dan usaha untuk mencegah gangguan involusi uteri yaitu dengan memberikan informasi tentang asupan nutrisi, menyusui dan mobilisasi dini, juga ada kerjasama antara berbagai pihak baik ibu nifas, keluarga dan petugas kesehatan.

Menurut (Abdillah and Putri, 2020) menunjukkan bahwa penyuluhan kesehatan melalui psikoedukasi merupakan salah satu cara untuk pencegahan depresi postpartum pada primipara, dan pemebrian booklet pada saat pemeriksaan kehamilan juga bisa sebagai sarana pencegahan depresi postpartum.

Menurut Yusuf, A., Armini, N. K. A., \& Nurfianti, A. (2007) menyatakan fase penyembuhan luka seksio sesarea berhubungan dengan tingkat stress pasien. Stress memicu peningkatan kortisol yang berdampak terhadap supresi imunitas seluler.

Menurut Mindasari, Y., \& Yulifah, R. (2017) menunjukkan bahwa ada hubungan stress ibu pre-operasi seksio sesarea terhadap penyembuhan luka operasi sesarea di ruang nifas Rumah Sakiit Ben Mari Malang. Disarankan kepada ibu-ibu yang menjalani pembedahan seksio sesarea sebaiknya dapat meminimalisir stress, mekanisme koping ditingkatkan dan dukungan sosial dari keluarga juga sangat diperlukan.

Dalam penelitian ini didapatkan pengaruh antara depresi post partum, mobilisasi dini secara bersama-sama terhadap involusi uteri. Hal ini sesuai dengan beberapa teori di atas yang meunjukkan bahwa dalam proses involusi uteri dibutuhkan informasi yang akurat kepada ibu nifas, sehingga ibu nifas dapat melampaui masa nifasnya secara normal, tanpa terjadi komplikasi pada masa nifas, terutama pada kondisi ibu post SC yang dimana membutuhkan informasi yang akurat tentang perawatan sebelum, selama dan sesudah operasi.

\section{Simpulan}

Kesimpulan yang dapat diambil adalah pada masa penyembuhan pasca persalinan operatif dibutuhkan suport dari berbagai pihak dalam hal ini petugas kesehatan dan juga keluarga untuk menekan resiko depresi post partum dan juga kegagalan melakukan mobilisasi dini yang bisa berefek pada involusi uteri

\section{Daftar Pustaka}

J. Rey, "Framework for action," Water Policy, vol. 3, no. SUPPL. 2001, doi: 10.1016/S1366-7017(01)00018-6.

Kemenkes RI, Profil Kesehatan Indonesia Tahun 2019, vol. 42, no. 4. 2019.

Riskesdas, Laporan Provinsi Jawa Timur Riskesdas 2018. 2019.

I. S. Yim, L. R. Tanner Stapleton, C. M. Guardino, J. Hahn-Holbrook, and C. Dunkel Schetter, "Biological and psychosocial predictors of postpartum depression: Systematic review and call for integration," Annu. Rev. Clin. Psychol., vol. 11, pp. 99-137, 2015, doi: 10.1146/annurev-clinpsy101414-020426.

S. ; M. S. Wahyuni, "Faktor Internal Dan Eksternal Yang Mempengaruhi Depresi Postpartum," J. Terpadu Ilmu 
Kesehat., vol. 3, no. 2, pp. 106-214, 2014.

T. W. Farida Mari'pi, "Hubungan Cara Persalinan dengan Tingkat Depresi Post partum di RSUD I . A," Bsr, vol. 1, no. 3, pp. 2203-2208, 2020.

J. Rottie and R. E. Saragih, "Pengaruh Mobilisasi Dini Terhadap Penyembuhan Luka Post Sectio Caesarea Di Irina D Bawah RSUP Prof DR. R.D. Kandou Manado," vol. 7, pp. 383-392, 2019.

S. Nurul and H. Saleh, "PROSES," vol. 4, no. 1, pp. 1-5, 2020.

D. Rahayu, A. Keperawatan, D. Husada, B. Lor, and K. Kediri, "mobilisasi dini pada ibu post SC," J. Keperawatan, vol. 11, no. 2, pp. 111-118, 2019.

Lisnawaty, Ernawati, and Hasmawati, "Faktor - Faktor Yang Mempengaruhi Involusi Uterus Pada Ibu Post Partum Di Rumah Sakit Khusus Daerah Ibu Dan Anak Pertiwi Makassar," J. Ilm. Kesehat., vol. 7, no. 5, pp. 565-571, 2015.

I. Rohmawati et al., "The Factors Affecting Uterine Involution in Post SC Mothers," in Journal of Physics: Conference Series, 2019, vol. 1175, no. 1 , doi: $10.1088 / 1742-$ 6596/1175/1/012284.

S. Silaen and S. Nurchayati, "Mekanisme Koping Ibu Yang Mengalami Postpartum Blues," Jom Psik, vol. 1, no. 2, 2014.

A. S. Habib and U. Ituk, "Enhanced recovery after cesarean delivery [version 1; referees: 2 approved]," F1000Research, vol. 7, no. 0, pp. 111, 2018, doi: 10.12688/f1000research.13895.1.

L. Marliza, "Pengaruh Mobilisasi Dini terhadap Proses Penyembuhan Luka." pp. 506-524, 2017.

Kustini, "Jurnal Kebidanan Universitas Islam Lamongan Vol. 10 No. 1, Juni
2018," J. Kesehat., vol. 10, no. 1, 2018, [Online]. Available: http://jurnalkesehatan.unisla.ac.id/ind ex.php/midpro/article/view/61/pdf.

A. J. Abdillah and S. E. Putri, "PENGARUH PSIKOEDUKASI

TERHADAP DEPRESI POSTPARTUM PADA IBU PRIMIPARA," J. Kesehat., vol. 7, no. 1, pp. 740-746, Mar. 2020, doi: 10.38165/jk.v7i1.114.

A. N. Ahmad Yusuf, Ni Ketut Alit A., "Stress Memperlambat Penyembuhan Luka Paska Seksio Sesaria," Univ. Airlangga, no. 47, 2007.

N. Ridhani, S. Prastiwi, and T.

Nurmaningsih, "Hubungan Stress Ibu Pre-Operasi Seksio Sesarea Terhadap Penyembuhan Luka Operasi Sesarea Di Ruang Nifas Rumah Sakit Ben Mari Malang," Nurs. News (Meriden)., vol. 2, no. 2, pp. 71-79, 2017, [Online]. Available: https://publikasi.unitri.ac.id/index.php /fikes/article/view/459/377. 